\title{
A study of the scutellum in eight Chagas disease vector species from genus Triatoma (Hemiptera, Reduviidae) using optical and scanning electron microscopy
}

\author{
Marcos Takashi Obara, João Aristeu da Rosa*, Walter Ceretti Jr, Paulo Roberto Urbinatti, \\ Lisardo Osório Quintero**, José Maria Soares Barata, \\ Cleber Galvão***/+, José Jurberg ${ }^{* * *}$
}

\begin{abstract}
Laboratório de Triatomíneos e Culicídeos, Departamento de Epidemiologia, Faculdade de Saúde Pública, USP, São Paulo, SP, Brasil *Laboratório de Parasitologia, Departamento de Ciências Biológicas, Unesp, Araraquara, SP, Brasil **Faculdade Nacional de Saúde Pública, Universidade de Antioquia, Medellin, Colombia ***Laboratório Nacional e Internacional de Referência em Taxonomia de Triatomíneos, Departamento de Protozoologia, Instituto Oswaldo Cruz-Fiocruz, Av. Brasil 4365, 21040-900 Rio de Janeiro, RJ, Brasil
\end{abstract}

The aim of this study was to analyze the external morphology of the scutellum through optical microscopy and scanning electron microscopy (SEM) in male specimens of Triatoma costalimai, T. delpontei, T. eratyrusiformis, T. matogrossensis, T. infestans melanosoma, T. sherlocki, T. tibiamaculata, and T. vandae. A total of 30 photographs of the scutellum were made. Magnification varied from 50X to 750X. Regarding depth and forms of the central depression, the heart-shaped form was predominant, with some exceptions, so that this shape appears to be a common characteristic for species of genus Triatoma Laporte, 1832. In T. eratyrusiformis, a kind of sensillum with important taxonomic value was observed. The different sizes and shapes of the designs found on the posterior process of the scutellum were also of important taxonomic interest. The study of the scutellum based on SEM showed valuable characteristics, allowing the use of this structure to aid the diagnosis of triatomine species. Thus, more specimens in subsequent studies and analyses of morphometric parameters should contribute to agreement on phylogenetic aspects in this genus. A Key to eight species of Triatoma based on male scutellar morphology is presented.

Key words: scutellum - optical microscopy - scanning electron microscopy -Triatominae - Chagas disease

Corrêa, in 1953, was one of the first researchers to study the morphological characteristics of the scutellum. By means of this structure's shape and length, the author expanded the generic distinction between Triatoma and Mepraia. Triatoma has a long scutellar apex, reaching the crossing of the clavi when the wings are folded, while the Mepraia has a short apex that does not reach the crossing of the clavi.

Lent and Wygodzinsky (1979) defined the scutellum as the posterior portion of the dorsal surface of the mesothorax, visible between the wings. They also highlighted the shape and details of the posterior process of the scutellum in genus Panstrongylus, showing that such characters are taxonomically important for separating species in this genus.

According to Carcavallo and Galíndez-Girón (1995), all species belonging to the genera Alberprosenia Martínez \& Carcavallo, 1979; Belminus Stål, 1859; Microtriatoma Prosen \& Martínez, 1952; Cavernicola

Financial support: Capes, Unesp, FSP/USP, CNpq, SVS-MS

+Corresponding author: clebergalvao@gmail.com

Received 17 October 2006

Accepted 12 March 2007
Barber, 1937; Psammolestes Bergroth, 1911; Eratyrus Stal, 1859; Panstrongylus Berg, 1979; and Triatoma Laporte, 1832 present specific patterns in the scutellum, not only in the shape and length of the body, but also in the cuticular structure, central depression, projections, and processes that allows its utilization in generic differentiation.

Carcavallo et al. (1996) used scanning electron microscopy (SEM) to view details in the shape and proportions of the scutellum in Triatoma ryckmani Zeledón \& Ponce, 1972, thus expanding the systematic and taxonomic knowledge of this species. Galíndez-Girón et al. (1997a) also used SEM to focus on the structural characteristics of the scutellum in Triatoma guazu Lent \& Wygodzinsky, 1979, proposing the inclusion of these pattern variations in future dichotomous keys. Under SEM, the scutellum can provide valuable taxonomic information, particularly for differentiating species, since this structure has a wealth of details, structures, and shapes that can definitely not be seen under conventional optical microscopy (Grimstone 1980, Carcavallo et al. 1994). Nevertheless, of the 138 described species, only $28 \%$ were studied with SEM for the shape, cuticular structure, pilosity, and relief of the scutellum and its posterior process, therefore little is known about this structure's absolute value as compared to other taxonomic elements (Carcavallo et al. 1997, Galvão et al. 2003).

The current study thus expands the morphological knowledge on the scutellum using SEM, describing the 
variations found in eight species of genus Triatoma, which currently consists of 85 species (Galvão et al. 2003, Costa et al. 2006, Costa \& Felix, 2007).

\section{MATERIAL AND METHODS}

The insects used in this study were from the collection of the Triatomines and Culicids Laboratory at the School of Public Health, University of São Paulo, the insectary of the Araraquara Special Health Service (SESA), an agency of the School of Public Health at the University of São Paulo, and the insectary of the Laboratório Nacional e Internacional de Referência em Taxonomia de Triatomíneos, Oswaldo Cruz Institute (IOC), Rio de Janeiro, Brazil.

The scutellum was studied on ten male adults of each species from different localities (Table). The scutella were dissected under a stereoscopic magnifying glass, dehydrated in serial alcohol, cleaned in acetone in ultrasound equipment, and attached with a double-faced adhesive tape to brass tori measuring $10 \mathrm{~mm}$ in diameter $\times$ $5 \mathrm{~mm}$ high, for metallization in carbon gold in a Sputter SCD 004 metalizer. After metallization, the specimens were analyzed under a scanning electron microscope $\left(\mathrm{JEOL}^{\circledR} \mathrm{JSM}\right.$ T-330A).

In the optical microscopy analysis, the scutella were also removed from the body of the specimens, dehydrated in serial alcohol and attached by double-faced adhesive tape to brass tori. The drawings were done in a ZEISS-Stemi SV6 light chamber.

The description of the results was based on the nomenclatures by the following authors: Carcavallo and Galíndez-Girón (1995), Galíndez-Girón et al. (1997b), Carcavallo et al. (1996), and Lent and Wygodzinsky (1979). A Key to eight species of Triatoma based on male scutellar morphology is presented.

\section{RESULTS AND DISCUSSION}

Aimed at a better understanding of the results, the scutellum was divided into two parts: the main body of the scutellum (CP) and the posterior process of the scutellum (PP). On the body, specific details were analyzed, like the overall shape, the shape of the lateral edges, the depth and shape of the central and median depressions, and the distribution of the sensillae. On the posterior process, the shape was observed together with that of the apex (Fig. 1).

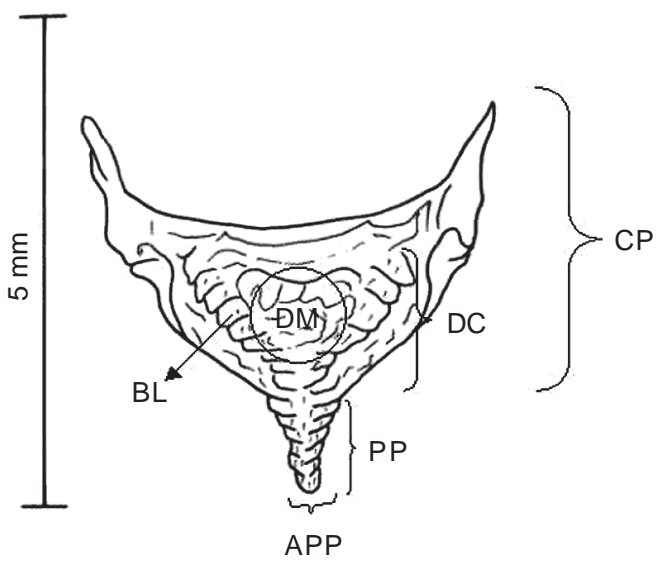

Fig. 1: scutellum of male of Triatoma vandae in light chamber drawing. CP: main body of scutellum; DC: central depression with sensillae; PP: posterior process of scutellum; APP: apex of the posterior process of scutellum; DM: median depression of scutellum; BL: lateral edges of scutellum.

Main body of the scutellum

Overall shape of body - All the scutella analyzed had a triangular shape (Figs 2A, B, C, D, E, F, G, H).

Lateral edges - T. delpontei, T. matogrossensis, T. costalimai, T.vandae, and T. sherlocki present heavily sculpted and irregular lateral edges (Figs 2A, B, D, F, $\mathrm{H}$ ), while in T. tibiamaculata, T. eratyrusiformis, and $T$. infestans melanosoma the lateral edges are lightly sculpted and regular (Figs 2C, E, G).

Depth and shape of central depression - The cordiform (heart-shaped) design predominated in most of the species studied, like T. delpontei, T. costalimai, T. vandae, and T. infestans melanosoma (Figs 2A, B, E, H). This aspect is similar in T. circummacuta, T. dimidiata, T. dispar, T. guasayna, T. infestans, T. patagonica, T. platensis, T. vitticeps, T. sordida, and M. pallidipennis as demonstrated by Carcavallo et al. (1997).

In relation to the extension of the central depression area, in T. delpontei, T. vandae, and T. matogrossensis it does not reach the base of the posterior process of the scutellum (Figs 2B, D, H). In other cases it reaches the posterior process, for example in T. costalimai (Fig. 2A) or extends beyond it, as in T. infestans melanosoma (Fig. 2E).

TABLE

Species, origin, and number of specimens studied

\begin{tabular}{llr}
\hline Species & Locality & $\begin{array}{c}\text { No. of male } \\
\text { specimens studied }\end{array}$ \\
\hline Triatoma costalimai & Luís Veloso, Goiás, Brazil & 10 \\
T. delpontei & Santiago del Estero, Argentina & 10 \\
T. eratyrusiformis & Argentina & 10 \\
T. matogrossensis & Goiás, Brazil & 10 \\
T. infestans melanosoma & Misiones, Argentina & 10 \\
$T$. sherlocki & Santo Inácio, Bahia, Brazil & 10 \\
T. tibiamaculata & Eldorado, São Paulo, Brazil & 10 \\
T. vandae & Itiquira, Mato Grosso do Sul, Brazil & 10 \\
\hline
\end{tabular}


In T. tibiamaculata, the central depression has a triangular shape, with the median portion showing shallow, horizontal sulci that end at the base of the posterior process of the scutellum (Fig. 2G). T. matogrossensis shows a slightly heart-shaped central depression. There can also be an accentuated rugosity on the median depression, but without reaching the base of the posterior process of the scutellum (Fig. 2D), as in T. lenti, characterized by Carcavallo et al. (1997).

$T$. eratyrusiformis has a W-shaped central depression, in addition to an evident depth in the basal portion of the median depression (Figs 2C, 3E). Lent and Wygodzinsky (1979) illustrated the central and median depressions of the scutellum in this same species as poorly defined (either not very linear or absent).

In $T$. sherlocki, the central depression of the scutellum is poorly defined, unlike the other species that were examined (Fig. 2F).

Sensillae - In relation to the concentration and distribution of the sensillae, the scutella were examined on the entire dorsal surface of the scutellar body and posterior process. For detailed observation of the sensillae, the same area was chosen for all the species photographed.

Although sensillae were observed on all the scutella that were studied, T. delpontei shows the greatest concentration and abundance of sensillae on the entire dorsal surface and posterior process (Figs 2B, 3F), similar to the case in T. lecticularia and T. platensis as observed by Carcavallo et al. (1997) and Carcavallo and GalíndezGirón (1995), respectively. The sensillae are less concentrated in T. tibiamaculata, T. infestans melanosoma, and T. eratyrusiformis (Figs $2 \mathrm{G}, \mathrm{E}, \mathrm{C}$ ). In the latter species, an important character is the type of sensillae, extremely thin as compared to those found in T. costalimai, $T$. vandae, and T. infestans melanosoma (Figs 3A, B, C, D).

Carcavallo et al. (1996, 1997), using SEM to study 27 species from genus Triatoma, did not find this type of sensilla in any of the species. Galíndez-Girón et al. (1997a), despite using 50X magnification, also found no similar sensillae in $T$. guazu. In $T$. sherlocki the sensillae are located mainly on the irregularities of the central depression and apical process (Fig. 2F).

Posterior process and apex of the scutellum - T. costalimai has a cylindrical posterior process, almost as long as the main body of the scutellum, narrow at the base and with pilosities that extend from the base to the apex, which is rounded (Fig. 2A).

The posterior process of the scutellum in T. delpontei is conical and long, with randomly distributed sensillae from the base of the process to the apex of the posterior process of scutellum, which is slightly truncated (Fig. 2B).

T. eratyrusiformis has a cylindrical posterior process, narrow at the base, reaching half of the main body of the scutellum, while the apex of the posterior process of the scutellum is clearly funneled and without transverse sculpting, unlike $T$. costalimai which is rounded (Figs 2C, 2A).

The posterior process of $T$. infestans melanosoma is conical, short, and clearly broad at the base, with scarcely evident transverse striations (Fig. 2E). Lent and
Wygodzinsky (1979) described the scutellum of $T$. infestans as entirely black, with a distinct central depression and a conical and horizontal posterior process, slightly more curved than the main body of the scutellum. Carcavallo et al. (1997), studying the scutellum of this same species using SEM, observed the presence of sensillae distributed throughout the posterior scutellar process. In $T$. infestans melanosoma, the concentration and type of sensillae, conical posterior process, elongated at the base, and extension of the central depression beyond the base of the posterior process presented morphological similarities to T. infestans infestans that did not allow the distinction between the subspecies by mean of the scutellar characters.

T. sherlocki is characterized by a cylindrical, short, small posterior process which does not reach halfway on the main body of the scutellum, with rather ringshaped transverse striations at the base of the process (Fig. 2F). This same figure shows the rounded shape of the apex of the posterior process.

In $T$. tibiamaculata, the posterior process is conical, long, broad at the base, and with a striated surface that extends halfway on the posterior process (Fig. 2G), similar to T. matogrossensis (Fig. 2D). The apical half is not striated. The apex of the posterior scutellar process is slightly blunt (Fig. 2G).

The comparison between our results and other species of the T. oliveirai complex show that the posterior process of the scutellum of $T$. jurbergi is pointed, almost as long as the main body of the scutellum, rounded in the apex (Carcavallo et al. 1998), unlike T. matogrossensis, which the posterior process of the scutellum is sub-cylindrical, slightly longer than half the main body of the scutellum, broad or extensive at the base, slightly rounded, with transverse sculpting that reaches half the posterior process of the scutellum, the apex of which is truncated (Fig. 2D). According to Carcavallo et al. (2001) the scutellum of T. klugi has the central depression deep and the posterior process conical and short. T. vandae has a sub-conical posterior process, narrow at the base, in addition to perceptible transverse sculptures along the entire process, including the apex (Fig. 2H). The sensillae are distributed randomly on these sculpted areas, between the center and the extremities, unlike T. matogrossensis, which has sculpting limited to half the posterior scutellar process, and does not display such sensillae (Figs 2D, H). The apex of the posterior scutellar process is truncated (Fig. $2 \mathrm{H}$ ).

The morphological study of the scutellum in eight species belonging to genus Triatoma Laporte, 1832 revealed important characteristics, especially in the shape of the central depression and posterior process.

Of all the species studied, four were heart-shaped. This shape appears to be a generic characteristic of this group, since according to data from the literature the majority of the species analyzed thus far display this pattern. However, some exceptions were found, such as T. tibiamaculata, T. eratyrusiformis, and T. sherlocki.

Differences in both the type and greater or lesser concentration of sensillae proved to be taxonomically important. 

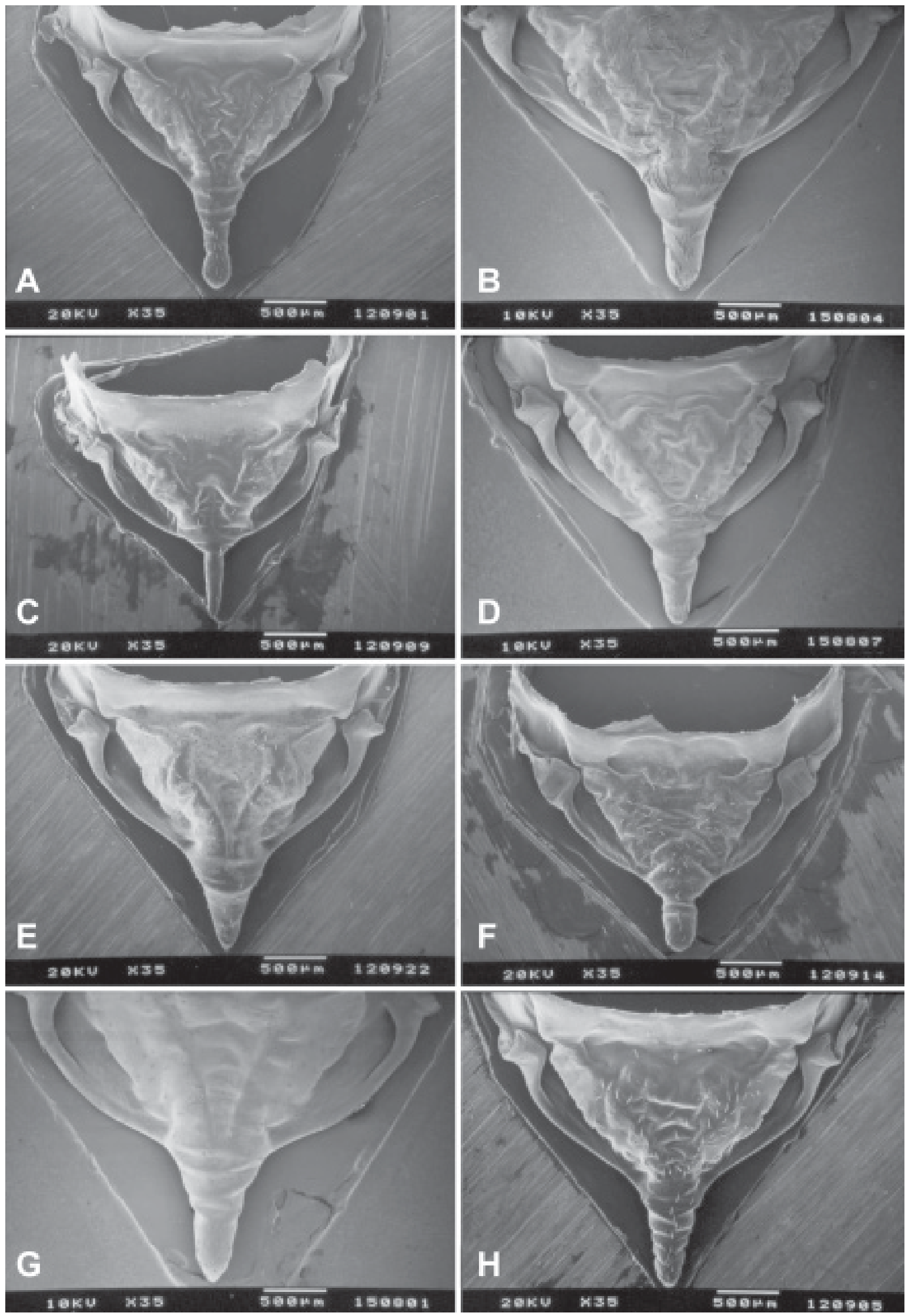

Fig. 2: photographs of the males scutellum of Triatominae species under scanning electronic microscopy (35X). A: Triatoma costalimai; B: T. delpontei; C: T. eratyrusiformis; D: T. matogrossensis; E: T. infestans melanosoma; F: T. sherlocki; G: T. tibiamaculata; H: T. vandae. 

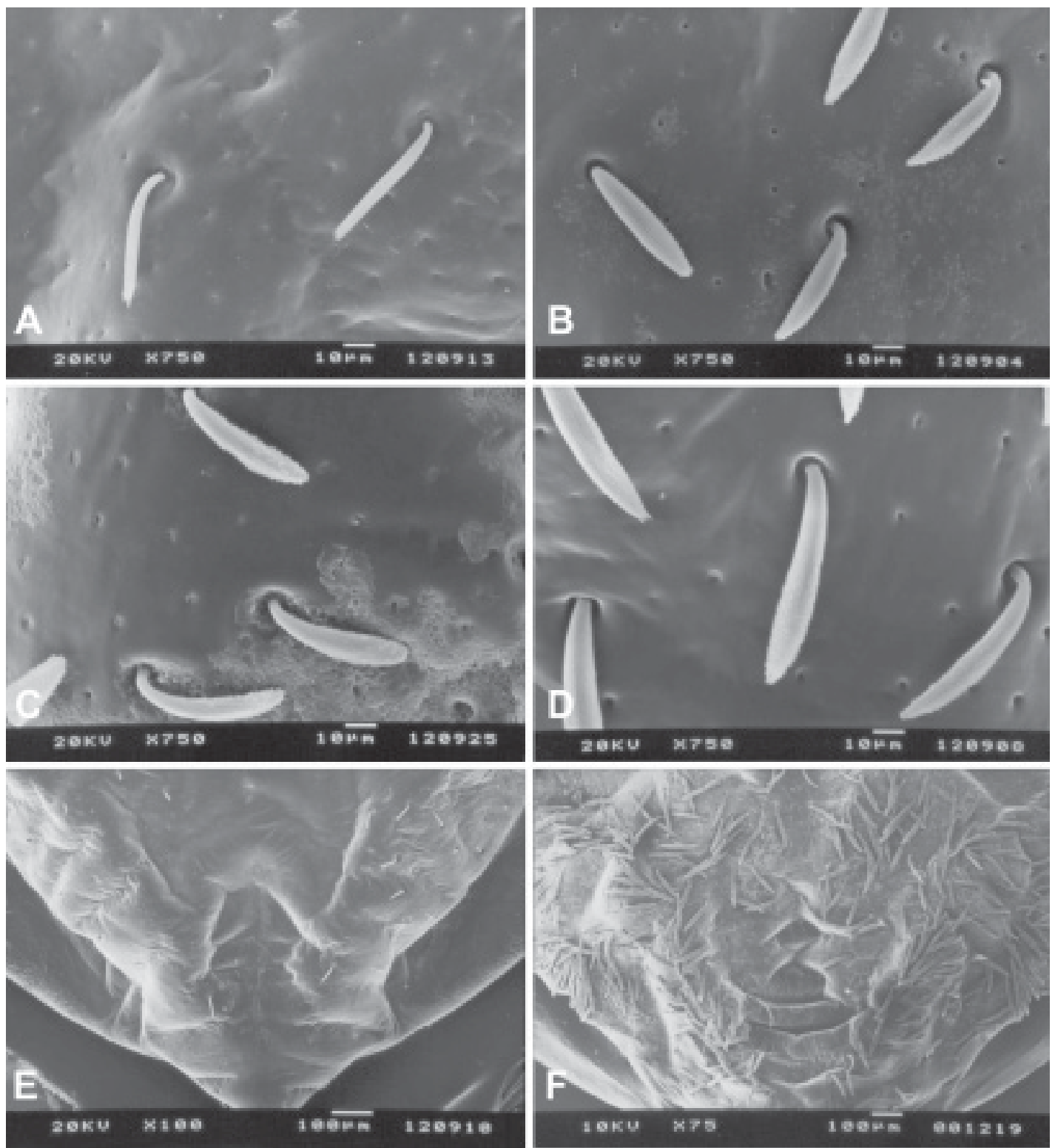

Fig. 3 A-D: types of sensillae on the males scutellum of Triatominae species under scanning electron microscopy (750X). A: Triatoma eratyrusiformis; B: T. costalimai; C: T. infestans melanosoma; D: T. vandae; E: scutellum of T. eratyrusiformis showing the W-shaped central depression; F: scutellum of $T$. delpontei showing the abundant sensillae.

The size, shape, and presence/absence of sculptures on the posterior scutellar process were systematically valuable. In other words, they allowed a specific distinction between T. eratyrusiformis, T. sherlocki, T. vandae, and $T$. matogrossensis, with the latter two species very morphologically similar.

Also, the characteristics of the lateral edges and apex of the scutellum proved relevant for diagnosing different species.

Finally, these morphological analyses indicate that more species should be observed to confirm the significantly important value of the scutellum for separating species.

Key to eight species of Triatoma based on male scutellar morphology

1. Lateral borders heavily sculpted and irregular Lateral borders slightly sculpted and regular
2. Area of central depression does not reach the base of the posterior scutellar process ............................................ Area of central depression reaches or extends beyond the base of the posterior scutellar process

3. Greater concentration and abundance of sensillae throughout the dorsal scutellar surface and posterior process delpontei Less concentration of sensillae on the dorsal scutellar surface

4. Central depression without a well-defined shape; short posterior process; sensillae located mainly on the irregularities of the central depression and apical process sherlocki Central depression with a different appearance .5

5. Cylindrical posterior process, almost as long as the main scutellar body, narrow at the base and with a rounded apex; 
bristles extending from base to apex costalimai

Posterior process without rounded apex ..6

6. Central depression slightly heart-shaped with accentuated rugosity in the median depression, which does not reach the base of the posterior scutellar process; posterior process with transverse sculpting that reaches the posterior scutellar process ...............matogrossensis Central depression heart-shaped with accentuated rugosity in the median depression, which reaches the base of the posterior scutellar process; posterior process with perceptible transverse sculpting along the entire process; presence of randomly distributed sensillae from the center to the extremities of the process vandae

7. Central depression W-shaped, with evident depth on the basal portion of the median depression; sensillae extremely fine; posterior process narrow at base; apex of posterior scutellar process clearly tapered and without transverse sculpting .... eratytusiformis Central depression not W-shaped .8

8. Central depression with triangular appearance and shallow horizontal grooves on median depression that end at the base of the posterior scutellar process, posterior process broad at base and with striated surface extending halfway on process; the other half is not striated tibiamaculata Area of central depression extends beyond the base of the posterior scutellar process; conical posterior process, short and clearly broad at the base and with barely perceptive transverse striations infestans melanosoma

\section{ACKNOWLEDGEMENTS}

To technician Sebastião from the Instituto de Química, Unesp, Araraquara for handling the scanning electron microscope, to Mr Gil, João, and Daniel Flores, Faculdade de Saúde PúblicaUSP, for technical assistance, and veterinarian Luiz CM Alencar for computational support.

\section{REFERENCES}

Carcavallo RU, Galíndez-Girón I 1995. Systematic value of the scuttelum in Triatominae (Hemiptera, Reduviidae). Entomol Vect 2: 23-29.

Carcavallo RU, Galíndez-Girón I, Catalá S, Jurberg J, Lent H, Galvão C, Barata JMS, Valderrama A 1997. Algumas estruturas anatômicas estudadas com microscopia eletrônica de varredura (MEV). In RU Carcavallo, I Galíndez-Girón, J Jurberg, H Lent (eds), Atlas dos Vetores da Doença de Chagas nas Américas, Fiocruz, Rio de Janeiro, Vol. I, p. 299-393.
Carcavallo RU, Galíndez-Girón I, Martínez A, Jurberg J 1994. Cuticular structures of Triatominae. Their taxonomic significance. Entomol Vect 1: 79-91.

Carcavallo RU, Galvão C, Lent H 1998. Triatoma jurbergi sp. n. do norte do estado do Mato Grosso, Brasil (Hemiptera, Reduviidae, Triatominae) com uma atualização das sinonímias e outros táxons. Mem Inst Oswaldo Cruz 93: 459-464.

Carcavallo RU, Jurberg J, Lent H, Galvão C, Steindel M, Pinto CJC 2001. Nova espécie do complexo oliveirai (nova denominação para o complexo matogrossensis) (Hemiptera, Reduviidae, Triatominae) do estado do Rio do Grande do Sul, Brasil. Mem Inst Oswaldo Cruz 96: 71-79.

Carcavallo RU, Zeledón R, Jurberg J, Galíndez-Girón I 1996. Morfologia externa de Triatoma ryckmani Zeledón e Ponce, 1972 vista através da microscopia eletrônica de varredura. Mem Inst Oswaldo Cruz 91: 727-731.

Corrêa RR 1953. Estudos sobre a morfologia externa do genus Triatoma Laporte, 1883 (Hemiptera, Reduviidae). Folia Clin Biologica 22: 23-50.

Costa J, Felix M 2007. Triatoma juazeirensis sp. n. from the state of Bahia, Northeastern Brazil (Hemiptera: Reduviidae: Triatominae). Mem Inst Oswaldo Cruz 102: 87-90.

Costa J, Argolo AM, Felix M 2006. Redescription of Triatoma melanica Neiva \& Lent, 1941, new status (Hemiptera: Reduviidae: Triatominae). Zootaxa 1385: 47-52.

Galíndez-Girón I, Carcavallo RU, Jurberg J, Lent H, Barth OM 1997a. Estudo morfológico de Triatoma guazu Lent e Wygodzinsky, 1979 (Hemiptera, Reduviidae, Triatominae). Mem Inst Oswaldo Cruz 92: 539-543.

Galíndez-Girón I, Torres E, Matos E, Araújo V, Márquez J, Barazarte R, Araque L, Castillo L 1997b. Estudio morfometrico preliminar de Rhodnius robustus Larrousse, 1927 (Hemiptera, Reduviidae, Triatominae) del Ocidente de Venezuela. Entomol Vect 4: 99-110.

Galvão C, Carcavallo RU, Rocha DS, Jurberg J 2003. A checklist of the current valid species of subfamily Triatominae Jeannel, 1919 (Hemiptera, Reduviidae) and their geographical distribution, with nomenclatural and taxonomic notes. Zootaxa 202: 1-36.

Grimstone AV 1980. O Microscópio Eletrônico em Biologia, EPU, São Paulo, 70 pp.

Lent H, Wygodzinsky P 1979. Revision on the Triatominae (Hemiptera,Reduviidae) and their significance as vectors of Chagas' disease. Bull Am Mus Nat Hist 163 :125-520. 